Ho, D. Y. F. (1995). Internalized culture, culturocentrism, and transcendence. Counseling Psychologist, 23, No. 1, 4-24.

\title{
Internalized Culture, Culturocentrism, and Transcendence
}

\author{
David Y. F. Ho
}

\begin{abstract}
Internalized culture is introduced as a psychological, rather than anthropological, construct most useful to counselors. It addresses explicitly both between-group and within-group variations resulting from individual differences in enculturation, and helps to sensitize counselors against overgeneralization and stereotyping. An explication of the construct leads to the problem of defining cultural boundaries. Serious difficulties in definition arise especially when three classes of phenomena are encountered: cultures in transition, cultures in contact, and bienculturation and multienculturation. Arguments are presented to advance the thesis that there is a basic continuity from intracultural to intercultural understanding. In a sense, all interpersonal encounters are cross-cultural in nature. Accordingly, all counseling requires an awareness of cultural processes and the transcendence of one's internalized culture.
\end{abstract}




\section{I nternalized Culture, Culturocentrism, and Transcendence}

What is meant by the expression crossing cultures? For counselors, the significance of this question translates into this: With which clients and at what point is the counselor engaged in multicultural counseling? There are good reasons why counselors have to be concerned with this question, given that they are more likely than ever before to face the problem of intercultural understanding and communication in their daily work. Confronting this problem compels us to examine more closely not only the meaning of crossing cultures but also the role of culture in all counseling processes. Thus, we would derive intellectual benefits for multicultural practice in particular and, more importantly, counseling in general. In line with the vision of multiculturalism as a fourth force in counseling (Pedersen, 1991), my aim is to challenge ourselves to a self-examination that has implications for the profession as a whole.

Exploring the meaning of crossing cultures entails an examination of the concept of cultural boundaries. Complications arise when we encounter three classes of phenomena: when a culture is undergoing rapid changes; (b) when cultures come into contact, often in conflict, with another; and (c) when individuals are enculturated to more than one culture. In this article, I discuss these phenomena in relation to the problem of cultural boundaries. The construct of internalized culture is first introduced as one most useful to counselors.

Transcending one's internalized culture is viewed as a key to counter egocentrism and culturocentrism--and to greater self-understanding. Arguments are presented to advance the thesis that there is a basic continuity from intracultural to intercultural understanding. Accordingly, all counseling necessarily entails an awareness of internal cultural processes. Finally, I discuss the implications of this thesis for counseling practice and training.

Internalized Culture

As counselors, we need to be informed of anthropological descriptions of modal and normative patterns of behavior. More importantly, we need to be concerned with individual differences, both qualitative and quantitative, in how people are actually exposed to, learn from, and are influenced by the culture to which they are exposed; that is, individual differences in enculturation. Accordingly, two levels of analysis are to be distinguished: The first regards culture as the basic unit of analysis and is concerned with intercultural or between-group differences; the second is focused on individual clients and is interested in not only intercultural but also intracultural or within-group variation. An appreciation of the distinction between cultural differences and individual differences within a culture is crucial to multicultural counseling. Yet, within-group variation has been a much neglected construct in multicultural psychology, counseling, and development (Ibrahim, 1991; Sundberg, 1981).

In this article, I attempt to explicate the construct of internalized culture. I argue that the conception of culture most relevant to counseling pertains not to the culture external to the individual, but to the culture internalized resulting from enculturation. Internalized culture may be defined as the cultural influences operating within the individual that shape (not determine) personality formation and various aspects of psychological functioning. Individual cognition, for instance, is influenced by internalized cultural beliefs.

Internalized culture must be distinguished from cultural group membership. It should be pointed out that cultural group membership per se is not a psychological variable, but internalized culture is--just as in themselves age, sex, and socioeconomic class are not psychological variables, but psychological maturity, gender, and class identification are. In effect, culture has been translated from an anthropological concept to a psychological or individual-level concept.

Differences in internalized culture arise from differences in enculturation. The concept of internalized culture explicitly addresses both between-group and within-group variations in cultural processes (see Carter, 1991, for a review of empirical research on cultural values). It enables us to better deal with findings that there may be more similarity among members of comparable socioeconomic statuses across groups than among members of different socioeconomic statuses within the same group. Very often cross-national or cross-ethnic differences decrease or even vanish when socioeconomic class is controlled. For example, 
Cashmore and Goodnow (1986) found that differences in parental values between AngloAustralian and Italian parents in Australia decreased when indicators of socioeconomic status were taken into account. Lambert (1987) reported a similar finding in a study of child-rearing values in ten countries.

Consider too subcultural differences within the same cultural group, between men and women, old and young people, or the rich and the poor. The evidence suggests that men and women in different groups are socialized differently (Pearson, Turner, \& Todd-Mancillas, 1991). It supports the contention that they have different internalized cultures and that, in a psychological sense, they belong to different subcultural groupings. Moreover, individual differences in internalized culture would be found among men and women alike. The same argument applies to the old and the young, as well as to the rich and the poor.

Contrasts With Anthropological Constructs

The idea of culture internalized is not new. Subjective culture analyzed by Triandis (1972) is also culture internalized. It refers to the characteristic ways people in each culture view the human-made part of their environment (ideas, social standards, and so forth). Among the concepts used to delineate subjective culture are worldview, cognitive map, life space, behavioral environment, and mazeway. A pattern of similar responses by members of a cultural group constitutes one aspect of the group's subjective culture. That is, subjective culture is a culture-level, not individual-level, construct. It is of limited utility for understanding individual worldviews and hence of limited importance to counselors. That no two individuals, even if they are from the same cultural group, share the same worldview requires assessment procedures that are more suited for counseling (see Ibrahim, 1991).

In giving emphasis to individual differences, internalized culture differs from anthropological concepts of culture. Kluckhohn (1954) distinguished two frames of reference, "inwardness" and "outwardness," in relation to the concept of culture: "For complete rigor, one might need to ... speak of Culture ${ }_{1}$ (the logical construct in the mind of the anthropologist) and Culture 2 (the norms internalized in individuals as manifested by patterned regularities in abstracted elements of their behavior)" (p. 924). The rigor of this distinction is less than complete, however. Culture 2 is logically also a construct "in the mind of the anthropologist"-- not to be equated with what actually exists in the mind of the individual member of a cultural group. It is focused on inward "patterned regularities," corresponding to the outward norms of Culture 1 .

Understandably, the focus on patterned regularities is common to cultural anthropologists, whose business is to construct conceptual models of the total culture (Culture ${ }_{1}$ ). These patterned regularities are assumed to be more or less shared in the collective minds of individuals belonging to a cultural group--virtually all anthropologists are agreed that culture is shared. However, in what form and to what extent culture is shared remains one of the enduring issues in culture theory (Rohner, 1984). A closely related issue concerns how cultural boundaries may be defined (discussed in the next section).

Given that the counselor's business is to work with individuals, singly or in groups, it is essential to avoid equating the internalized culture existing in the mind of the client with notions of shared patterned regularities held by theorists. Informed by these notions about a cultural group, counselors are vulnerable to activate automatically expectations and judgments about clients from that group--that is, to apply knowledge about a group to make judgments about individuals (cf. Murphy, 1977). But there is a danger of overgeneralization and even stereotyping. The form and extent of a client's sharing of the patterned regularities must be investigated empirically and not taken for granted. Indeed, such investigation is part and parcel of counseling assessment. Of special importance is the sensitivity to discrepancies, tensions, and conflicts, which may exist side by side with conformities, between the client's beliefs and values and those shared by members of his or her cultural group. Furthermore, these discrepancies, tensions, and conflicts are not to be viewed necessarily in a negative light. They may be the driving forces for adaptation, creativity, and change.

Sensitivity Against Overgeneralization and Stereotyping

A major advantage of relying on the concept of internalized culture, then, is that it helps to sensitize counselors against overgeneralization and stereotyping. Though often used 
interchangeably in multicultural counseling, overgeneralization and stereotyping are distinct concepts. Clarification is needed. A generalization is a statement about the characteristics of a cultural or ethnic group made on the basis of observations, often limited, of some of its members. As long as it is borne in mind that generalizations are only unavoidable approximations of reality, they may be permissible and useful. An overgeneralization is an unwarranted generalization because the observations are overly limited, made on too few or unrepresentative members, or both. It takes the form of an assertion about an entire group of individuals or an overinclusive domain of characteristics of the group.

Stereotyping goes beyond overgeneralization in that it connotes rigidity. English and English (1958) define stereotype as "a relatively rigid and oversimplified or biased perception or conception of an aspect of reality, esp. of persons or social groups" (p. 523). Stereotyping assumes an extreme form when a whole group of people is viewed solely on the basis of their group membership; individual identities are obliterated. Racism, sexism, and ageism are forms of discrimination rooted in stereotyping. And ethnic cleansing and genocide are the most tragic consequences of racism. Given their avowed aversion to overgeneralization and stereotyping, one would ask why counselors seem perennially mired in a preoccupation with these "cardinal sins." A partial answer to this question requires an examination of the literature and possible misreadings of research findings by counselors.

The research literature is replete with studies which classify individuals arbitrarily according to the national, ethnic or racial group to which they "belong." Common practice is, however, often a poor guide to sound research. National or ethnic group membership does not necessarily correspond to cultural group membership. Multicultural or multiethnic groups may live in the same country, and some ethnic groups living in different countries share the same culture; also, cultural or subcultural diversity may be found within ethnic groups, and different ethnic groups may share elements of the same culture. Cross-national or crossethnic studies are, therefore, not to be confused with cross-cultural studies. Most important, because neither human geneticists nor anthropologists have reached a consensus on definition, the term race is often used incorrectly (Yee, Fairchild, Weizmann, \& Wyatt, 1993).

Studies which classify people according to national or ethnic group membership tend to lead us into the habit of focusing attention on group differences. A less innocuous tendency is to overgeneralize or to think in terms of static stereotypes. As consumers of the research literature, practioners share the responsibility for this tendency when they confuse three separate ideas: statistical significance, scientific meaningfulness, and practical usefulness. Unfortunately, researchers often report statistically significant differences, without also reporting the corresponding effect sizes (e.g., group mean differences expressed in standard deviation units). Obtained results then constitute the empirical basis for generalizations about the relative psychological characteristics or functioning of the groups compared. (Because Americans have been the most extensively studied, they have almost come to be taken as the standard reference group against which other groups are compared. However, the American pattern may be more atypical than typical from a global or historical perspective.) Now consider that the power of statistical tests (the probability of rejecting the null hypothesis) is a function of sample size (see Cohen, 1965, for an extended discussion). Given a sufficiently large sample, even minute group differences may reach a preset level of statistical significance. But such group differences, of possible scientific meaningfulness in basic research, are of little practical value for discriminating individuals from one group to another.

It is disheartening to find in the literature on ethnicity and multicultural counseling too many instances of overgeneralization and ethnic stereotyping that serve more to mislead than to illuminate--despite the authors' own cautionary statements against doing so. In McGoldrick's (1982, p. 11) overview of ethnicity and family therapy, I counted on a single page a total of 11 ethnic groups about whom the author made sweeping generalizations: "WASPs may be concerned about dependency or emotionality" and "tend to see work, reason, and stoicism as the best solutions" to their problems; Norwegians "may tend to see their problems as the result of their own sin, action, or inadequacy" and "might prefer surgery, fresh air, and exercise" as the solution; Greeks "may tend to see their problems as the result of ... somebody else's [sin, action, or inadequacy]" and may be concerned about "any insult 
to their pride"; and so forth.

Like McGoldrick, Sue and Sue (1990) aim to reduce ethnic stereotyping, and have cautioned the reader against making overgeneralizations. Unfortunately, their aim has been marred by failing to exercise such caution. On page after page the reader finds expressions such as "White social science," "White Male Professor," and "White Counselor." Sue and Sue (1990) speak of developing a "nonracist White identity"--given that "all Whites are racist whether knowingly or unknowingly" because they "are socialized into U.S. society and, therefore, inherit the biases, stereotypes, and racist attitudes, beliefs, and behaviors of the society" (p. 113). Curiously, missing from the discussion is the development of nonracist identities by non-White groups-- with the implication that racism is a White monopoly.

Besides being imprecise, the term White (especially when referring to males) appears to have already acquired pejorative connotations in the United States. I deplore its continued use and prefer the term Euro-American. (For a discussion of the problems of race labeling, see Dobbins \& Skillings, 1991; Yee et al., 1993.)

The Problem of Cultural Boundaries

Explicating the construct of internalized culture invites us to confront the question: How do we know when we are "crossing" cultures? This question is critical to the theoretical foundation for culture-specific versus client-specific counseling (discussed in the Implications for Practice and Training section). The term cross-cultural itself predisposes us to think in spatial terms: cultural groups located in different countries or geographical settings. But the analysis above shows that we cannot even begin to tell when a person is crossing cultures, until we have a sharper conception of cultural boundaries.

The notion of crossing cultures seems to imply the existence of distinct cultural units with identifiable boundaries. Attempts to define these units have long absorbed the energy of many anthropologists. A cultural group is supposed to refer to a group of individuals who share a common culture. But what is shared, what is "common," and what marks a culture apart from other cultures? It is misleading to speak of, for instance, Native-American culture as if it were a single monolithic entity, when in fact it is so rich in ethnic and linguistic diversity. This brings us to confront the boundary problem.

\section{Unit Definition}

Time, place, and language are obviously three differentiating factors of basic importance. Naroll's (1970) approach to unit definition, which has gained widespread recognition, employs the cultunit concept. A cultunit encompasses "people who are domestic speakers of a common distinct language and who belong either to the same state or the same contact group" (p. 731). The double-language boundary method is proposed to establish language boundaries (Naroll, 1971). Instead of trying to establish one boundary between two language communities, we proceed in two directions: from language $A$ to language $B$, and from language $B$ to language $A$. If a boundary is established in both directions, that is, if mutual unintelligibility is indeed found, we may treat the two language communities as two cultunits.

The definition of cultural units is useful for investigations at the group or population level. For cross-cultural research, classification based on well defined cultural units is an improvement over that based on national or ethnic group membership. However, this approach reduces culture to the status of a nominal variable, and is thus inherently limited. First, categorical assignment presumes that each subject belongs to one, and only one, cultural unit. This presumption is untenable in the case of fully bicultural or multicultural individuals. Second, subcultural variations arising from potent factors such as age, sex, and socioeconomic class are ignored. More fundamentally, within-group individual differences in enculturation, and hence in the extent to which culture is internalized, cannot be dealt with. Cultural differences are thus reduced to differences in kind, not in degree. Third, culture is treated as a unidimensional variable; the multidimensional nature of cultural processes (e.g., language acquisition, socialization, and cultural cognition) is not addressed.

Moreover, boundaries are not static. Unit definition runs into serious difficulties when a culture is undergoing rapid changes or when cultures come into contact, often in conflict, with each other. Cultures in contact may expose and enculturate individuals to more than one culture, resulting in biculturalism and even multiculturalism. These phenomena present a 
fresh challenge to multicultural counseling and compel us to adopt a more dynamic conception of cultural processes.

\section{Cultures in Transition}

This concerns the issue of continuity versus change within cultures through time--one demanding urgent attention as we witness accelerated sociocultural changes taking place in the modern world. Unfortunately, cross-cultural researchers have paid more attention to synchronic studies (i.e, those of a process at one point in time) than to diachronic studies (i.e., those of a process as it changes over time). Culture is typically treated as a static variable, as if it were frozen in time; the temporal dimension is ignored. It is tacitly assumed that members of the same cultural group can be lumped together, regardless of age or generational differences. This assumption may be acceptable if the culture in question is relatively stable. In studying a rapidly changing culture, however, the need to consider age or generational differences becomes salient.

When a culture is undergoing rapid changes, a delineation of its traditional pattern is not only of interest in its own right but also of strategic importance. It would provide us with a stable frame of reference against which the extent, momentum, and direction of change can be gauged. With these considerations in mind, several methods to chart the course of cultural changes may be used. The most straightforward is to use the same instruments that measure some aspects of culture to collect and compare data on comparative samples at different times. Another is the use of content analysis of cultural productions (e.g., stories, popular sayings, and films). A third is to study intergenerational differences through the use of families, rather than individuals, as the units of analysis (e.g., Ho \& Kang, 1984).

Another issue to be considered is that many ethnic groups sharing a common cultural heritage are located in different countries or diverse geographical settings. Conceptually the issue of continuity versus change over a period of time is distinct from that of variance versus invariance across geographical locations. In practice, however, it is difficult to investigate one without dealing with the other at the same time. For continuities with, and departures from, cultural tradition may differ radically, depending on geographical location. Furthermore, important variables, such as age, sex, and socioeconomic class, interact with both temporal and spatial variables, thus giving rise to variation in continuities and departures (Ho, 1989).

Culture is usually thought of as being conservative and enduring in nature. However, noticeable cultural changes may be documented even within a limited time span of several decades. For example, Ho and Kang (1984) reported that changes in paternal attitudes toward filial piety in Hong Kong are in evidence between only two generations, which is a very short time span indeed in terms of cultural change. Yet, in a review of the literature on Chinese patterns of socialization, Ho (1989) concluded that: "Despite important variations across geopolitical boundaries, common features that are distinctively Chinese in character may be discerned; and despite undeniable changes over time, continuity with the traditional pattern of socialization is preserved among the Chinese of today" ( $p .160$ ). These studies prompt us to regard culture as both malleable and resilient: malleable because it is modifiable by both internal and external influences, and resilient because cultural traditions show a remarkable capacity to survive and preserve their continuity over time. Cultures in Contact

This brings us to the domain of acculturation research. Historically it has been focused on the acculturation of Third World societies to Western industrialized societies, of immigrant groups to the host culture, or of minority group and race relations within countries (Olmedo, 1979). Conceived more broadly, however, acculturation is the process--which may be bidirectional--whereby members of a cultural group learn and assume the behavior patterns of another cultural group to which they have been exposed. Increasingly, modern life in diverse geographical settings is characterized by cultural interpenetration and crossfertilizations; hence, to varying degrees acculturation cannot be avoided. If enculturation, which involves presumably only one culture, is complex, so much more acculturation must be. New dimensions of cultural processes have to be explored. How do people adapt when they are confronted with cultural forces alien to their culture of origin? Under the condition of cultures in contact, often in conflict, both the strengths and weaknesses of a culture may be brought into sharper focus and nakedly revealed. 
Equipped with the concept of internalized culture, we may translate the research problem into one of investigating acculturation as a psychological phenomenon at the individual level. This requires, as a first step, the identification and measurement of acculturation variables pertaining to individuals. In studies of immigrants, for example, a crude index of cultural exposure is the ordinal generation of the individual born in the host culture. A more refined index would include measures of the quantity and well as the quality of exposure.

Olmedo (1979) advocates a psychometric perspective to the measurement of acculturation. Three main categories of items have been used in the construction of scales for measuring individual acculturation: linguistic (e.g., language proficiency, preference, and use), sociocultural (e.g., socioeconomic status and mobility, degree of urbanization, family size and structure), and psychological (e.g., cultural value orientations, attitudes, knowledge, and behavior). The use of psychological scales, in particular, shifts the emphasis in ethnicity studies from ethnic group membership (in itself not a psychological variable) to ethnic identity and loyalty. (One would not assume that there is a necessary correspondence between these two variables.) Olmedo concludes that acculturation is measurable with reasonable reliability and validity; that it is a multidimensional process, as the linguistic, sociocultural, and psychological measures appear to be largely independent of one another; and that there may be a remarkable degree of heterogeneity in the level of individual acculturation.

Bienculturation and Multienculturation

Expecting to find externally or spatially located cultural boundaries is absurd once we go beyond acculturation and encounter the phenomenon of bicultural and multicultural minds. Here, I coin two technical terms, bienculturation and multienculturation, referring to enculturation to more than one culture (e.g., as in the case of children of parents from diverse cultural backgrounds). They differ from acculturation in that no one culture is regarded as the host or dominant; assimilation, a unidirectional process, is not the object of interest. Rather, different cultural systems are internalized and coexist within the mind. At the group level, there is no necessary distinction between the ingroup and the outgroup to speak of. Bienculturated or multienculturated persons are not merely exposed to and knowledgeable of, but have in-depth experiences and hence competence in, more than one culture. In short, the internalized culture of these persons embodies a plurality of cultural influences of diverse origins.

Unlike bilingualism, biculturalism has yet to receive the attention it deserves in research. Nevertheless, we may borrow concepts from the extensive psychological and psycholinguistic literature on bilingualism (e.g., Hakuta, 1986; McLaughlin, 1984). Second-culture acquisition, a term used by LaFromboise, Coleman, and Gerton (1993), corresponds to second-language acquisition. Bienculturation in childhood corresponds to simultaneous bilingual acquisition; acculturation corresponds to successive bilingual acquisition, in which second-language learning takes place after a first language has already been firmly established. Fully bienculturated individuals correspond to balanced bilinguals. Intercultural value conflicts correspond to linguistic interference. Finally, the thesis of cultural determinism corresponds to Whorf's (1956) hypothesis of linguistic determinism, according to which language determines the shape of thought.

Studies of individuals enculturated to more than one culture can inform us on how different cultural systems can be integrated, or fail to integrate, within single minds--a fascinating question by any standard. If indeed culture shapes cognition, then how is the cognition of the bienculturated individual structured? Does bienculturation or, better still, multienculturation inoculate one against culturocentrism? How are intercultural value conflicts handled? Would a new supracultural identity emerge, or would multiple identities, perhaps with little permeability among them, be the result? Creative synthesis and compartmentalization represent, of course, only two of the many possibilities. In reviewing the literature on the psychological impact of biculturalism, LaFromboise et al. (1993) emphasize the alternation model of second-culture acquisition. According to this model, people are able to gain competence within two cultures without losing their cultural identity or having to choose one culture over the other. It is an additive model of cultural acquisition corresponding to code switching in bilingualism. In this regard, bienculturated individuals would have a distinct advantage. 
Bienculturated and multienculturated individuals constitute a valuable resource for intercultural understanding. They are in a specially advantageous position to interpret intercultural events, because they are equipped with alternative cognitive maps. To this extent, they may be better inoculated against culturocentrism. They may more effectively serve as agents for combating racism and promoting intercultural understanding.

LaFromboise et al. (1993) suggest that ethnic minority people who acquire bicultural competence will have better physical and psychological health than those who do not. I would emphasize that bicultural competence is an asset for the ethnic majority as well. Opportunities now exist in the United States and elsewhere, more than ever before, for individuals from various groups to be bienculturated and acquire bicultural competence. No longer viewed as marginal individuals, they may even be models for the creation of world citizens in the not-too-distant future.

Inherent in multiculturalism is the dialectic tension between two tendencies: diversity and unity. Diversity without unity leads to factionalism, and unity without diversity is boring uniformity. (See Mio \& I wamasa, 1993 for an account of the tension in a recent APA symposium aimed to examine the Euro-American researcher in multicultural counseling.) I submit that a deliberate attempt to cultivate more bienculturated and multienculturated individuals offers the best hope for attaining unity with diversity.

Transcending One's Internalized Culture

The notion of crossing cultures is deceptively simple. It turns out to be far more complicated than going from one cultural group to another. From a psychological perspective, we may be crossing cultures even within the same cultural group, when potent factors such as sex, age, and socioeconomic status are addressed. Moreover, are we not also crossing cultures each time we encounter individual differences in internalized culture--bound to be found between any two individuals, given our reaffirmation of individual uniqueness? Following this argument to its ultimate, we may ask further: How does crossing cultures occur within the mind of the bienculturated individual?

We are compelled to reach the conclusion that, psychologically speaking, we may take a cross-cultural journey within our own cultural group. Moreover, all encounters between any two individuals are, in a sense, cross-cultural encounters. The theoretical significance of this proposition is that cultural processes are ubiquitous in all interpersonal interactions. More startling is the realization that a cross-cultural journey may be taken within a single bienculturated mind.

There is thus a psychological continuity from intracultural to intercultural understanding: One is invariably challenged by the need to transcend one's internalized culture. At rock bottom, all interpersonal understanding, be it intracultural or intercultural, entails transcending egocentrism. In general, the greater the interpersonal distance in psychological maturity, class identification, and so forth, the more impediments in interpersonal understanding are likely to be present. A quantum increase in difficulty is encountered when the persons involved come from diverse cultural backgrounds. In addition to egocentrism, culturocentrism has to be overcome. But it is doubtful if culturocentism can be overcome without first attacking egocentrism.

This may be an unexpected benefit from asking the question of what is meant by crossing cultures: to be reminded of the uniqueness of the individual and of the ubiquitous need for transcendence in the understanding between individuals. The concept of internalized culture compels us to recognize individual differences in internalized culture, arising from differences in enculturation. Even among members of the same cultural group, no two individuals would be expected to have an identical internalized culture. The uniqueness of the individual is reaffirmed.

Closely related to internalized culture are two psychological concepts that hold a promise to liberate us from the rigidity of looking at people solely in terms of their cultural membership. The first, cultural identification, acknowledges that individuals may differ widely in the extent to which they identify with the cultural heritage of their group or those of other groups. The second, cultural orientation, reaffirms a measure of autonomy in individual preference for various cultural patterns. It is a concept of special significance to the identity 
of bienculturated and multienculturated individuals. A great opportunity is present for them to articulate a supracultural value system, such that value judgments and moral reasoning are no longer anchored to a single culture (cf. LaFromboise, 1993). Cultural identification and cultural orientation are thus instrumental to the development of self-identities and worldviews (cf. Myers et al., 1991). The more integrated the individual's identity is, the more likely healthy coping patterns will be present (Murphy, 1977).

I mplications for Practice and Training

The discussion of cultural boundaries accentuates the need for a more dynamic conception of cultural processes, and for attending to the phenomena of cultures in transition, cultures in contact, and bienculturation and multienculturation. The preoccupation with ethnic or cultural group membership has resulted largely in a sterile conception, or worse, overgeneralization and stereotyping. It is time to make use of better intellectual tools that meet the counselors' needs, such as internalized culture, cultural identification, and cultural orientation.

The analysis above invites us to see how programs presumably designed to enhance interethnic understanding often perform a disservice when they dwell on differences between groups, at the expense of appreciating similarities between and individual variation within groups. Likewise, much of the literature on multicultural counseling may be faulted for treating intercultural understanding as if it were discontinuous, or fundamentally different, from interpersonal understanding. The implication is that there is a need to invent new principles and techniques for different cultural groups.

Treating the "Culturally Different" Differently?

Sue and Sue (1990) contend that there is a need for developing culture-specific communication and helping styles for culturally different clients. The term culturally different leads us into a conceptual conundrum. Different from whom? From White Anglo-Saxon Protestants (WASPs), the reader is told. Of course, there is nothing to preordain WASP culture as the foundation for counseling, or to preclude the cultural heritage of other groups to nourish its growth. For example, de Silva (1993) has made a case that Buddhist psychology is relevant and has much to contribute to present-day therapeutic practice.

To insist on having a separate treatment for each distinct group is theoretically and practically unsound. We have already seen the complexities entailed in the definition of cultural boundaries. Taking the case of Asian-Americans alone, we would need different treatments for Chinese-Americans, Filipino-Americans, Indian-Americans, and so forth. I nasmuch as every group is "culturally different" from every other group, further subdivisions would be needed within each. For example, we would need different treatments for different Chinese-American groups originating from mainland China, Taiwan, Hong Kong, and so forth. To lead the argument to its logical conclusion, still more refined differentiations are to be made--only to result in an unmanageable multiplicity of approaches to counseling. Let us beware of misguided multiculturalism leading us into the blind alley of particularism.

The theoretical ancestry of culture-specific counseling, largely unacknowledged, may be traced to the culture and personality studies from which their offspring, the concept of national character (Inkeles \& Levinson, 1954), was begotten. It is a concept fraught with difficulties, among which is inherent stereotyping (Favazza \& Oman, 1980); and it has fallen into scientific disrepute. A closely related ancestry is the thesis of cultural determinism. As stated by White (1948): "Human behavior is merely the response of the organism to cultural stimuli. Human behavior is determined, therefore, by culture" (p. 244). Cultural determinism lends itself dangerously to overgeneralization and tends to promote culture-specific, rather than client-specific, approaches to counseling. The tacit assumption is that, if culture determines behavior and if members of a group share the same culture, then the approach to counseling them should be based on principles and techniques appropriate to their specific culture.

There are grounds for objecting to cultural determinism. First, cultural determinism cannot account for "intracultural variations and individual differences with respect to virtually every cognitive, behavioral, and motivational domain" (Rohner, 1984, p. 116). Hence, "individual personality cannot be predicted directly from knowledge of the culture or social system" (Rohner, 1984 p. 123). 
Second, human beings are both the products and the creators of culture. In line with Bandura's (1978) concept of reciprocal determinism, the relation between individual behavior and culture is best conceived as one of continuous interaction. There is no intrinsic reason why culture has to be treated as the cause, and individual behavior as the effect. If culture is defined as that part of environment created by human beings, then we create environments that, in turn, make us human.

Third, the strict view that culture determines behavior negates psychological universals. It implies the proposition that different cognitive systems correspond to different cultures-and raises the question of how people from different cultural backgrounds can understand and communicate with each other at all. The absurdity of this proposition is revealed in the case of the bienculturated person. It raises the specter of a schism between two separate cognitive systems within a single mind--and thus the question of how internal communication between two compartments of the same mind, each operating under its own cognitive system, is possible. The existence of bienculturated minds without such schism demonstrates that human beings have the amazing capability to integrate diverse cultural influences into a cognitive whole at increasingly higher levels. Extending this argument to counseling would negate the claim, sometimes made by misguided mental health professionals, that persons in need of help can or should be helped only by professionals belonging to the same ethnic or cultural group. Equally negated is the contention that Euro-American researchers have no business studying minority issues (see Mio \& I wamasa, 1993).

Advocates of culture-specific counseling (Nwachuku \& Ivey, 1991; Sue \& Sue, 1990) are rightly motivated by the desire to rectify a wrong, namely, using culturally inappropriate (i.e., "traditional") principles and techniques to counsel different cultural groups. However, what is culturally appropriate cannot be predetermined from a knowledge of the client's culture alone (I brahim, 1991; Sundberg, 1981). Thus, counseling specifically designed for a minority group may be inappropriate to many of its members. Likewise, traditional counseling based on Euro-American values may be inapplicable to a large segment of Euro-Americans. In particular, culture-specific counseling is theoretically ill equipped to treat bienculturated clients.

The concept of internalized culture, on the other hand, promotes at once cultural sensitivity and client-specific counseling. Internalized culture functions like a cognitive map to guide one's social actions through the social terrain. It influences the formation of our worldviews, which may be broadly defined as a set of presuppositions underlying our views about the world and our place in it. I brahim (1991) accords the construct of worldview central importance in generic counseling. An operational procedure is described to assess both the counselor's and the client's worldview and cultural identity. This procedure promises to help overcome the limitations inherent in culture-specific counseling that relies on a knowledge of the client's culture alone.

Accusations and Guilt Induction

Stronger claims too, damning Western or traditional practice, have been made. Pedersen (1988) asserts: "It is increasingly clear that Western style mental health services are inappropriate, too expensive, too dependent on technology and are frequently destructive to the non-Western host setting" ( $p .83$ ). He presents no evidence on the alleged destructive effects. One would also question how appropriate and cost-effective are the Western services in Western societies as well. For instance, as they are presently constituted, the emphasis is placed on cure rather than prevention.

Sue and Sue (1990) believe that "traditional counseling theory and practice have done great harm to the culturally different"; accordingly, there is a need to develop "new methods, concepts, and services more appropriate to the life experiences of culturally diverse groups" (p. v). The validity of their accusation rests on three dubious assumptions: (a) Counseling theory and practice can be dichotomized into two broad categories, "traditional" and "nontraditional" (based on "new methods, concepts, and services"); (b) traditional counseling theory and practice have done more harm to the culturally different than to mainstream EuroAmericans; and (c) traditional counseling theory and practice have done more harm than the nontraditional to the culturally different. A more balanced view would be that, as in other domains of healing, traditional counseling has the potential to do harm, as well as good, to 
individuals in any cultural group. Is it not an elementary requirement of all counseling to consider the unique life experiences of the client in any case, and adjust one's approach accordingly?

Accusations of culturocentrism have activated the professional superego of cross-cultural psychologists (Ho, 1992). They activate the professional superego of counselors as well, resulting in varying degrees of guilt. A rather unhealthy tendency may be discerned: Having been intimidated by these accusations, many counselors become timid and apologetic (i.e., more polite and less frank) when interacting with minority clients--a reaction formation? All kinds of behavior, including those disapproved by members of minority groups themselves, are conveniently "explained" (i.e., excused) in terms of their historico-cultural backgrounds. The apologetic, "nonjudgmental" stance may take refuge in the name of cultural relativism. It may even degenerate into corrupted moral relativism: a curious and dangerous position denying that there are irreducible standards for human conduct. Or, it may take the form of insulting double standards: Behavior regarded as undesirable or performance regarded as unsatisfactory by Euro-American standards may be regarded as "normal" if it is displayed by minority clients!

How can intimidated and guilt-ridden counselors function effectively? How can they fulfill their socially responsible roles as cultural critics and agents of social change--for EuroAmericans as well as for minority groups?

Promoting a Comparative Frame and Psychological Decentering

A key point is that enhancing awareness of cultural diversity has value for understanding not only another person's culture but also one's own, and ultimately for greater selfunderstanding. Such awareness facilitates psychological decentering through adopting a comparative frame of mind that liberates people from viewing the world through only one cognitive system rooted in a culture, that is, from cultural encapsulation. A strong claim may be made: Those who do not know the culture of others do not really know their own.

Psychological decentering is thus therapeutic to guilt-ridden researchers and professionals (Ho, 1992).

Now to know the culture of another is to discern how it is different from, and similar to, one's own; that is, to make comparisons. From this perspective, the aversion to comparisons, expressed by some leaders in multicultural counseling, seems strange. Pedersen (1988) states that, "by implying comparison, the terms crosscultural, intercultural, and transcultural sometimes implicitly suggest that one culture is better than the other" ( $p$. viii). Is that the only way in which cultures may be compared? Likewise, Corey, Corey, and Callanan (1993, p. 241) states that the term multicultural is preferred, because it avoids any implied comparison. But is avoiding comparisons possible? Without comparisons, cognitive activity would cease.

In multicultural counseling, ethnocentrism or, more precisely, culturocentrism, has long been regarded as an impediment to be overcome. To avoid the pitfalls of culturocentrism is to transcend one's internalized culture. Even without the advantage of the bienculturated mind, a serious counselor can nonetheless go a long way toward combating culturocentism. Ho (1992) has developed a metatheory of cross-cultural comparisons that promotes an intellectual attitude of decentering to observe its effects and to modify it through selfreflection--a unique human capability, without which there would be no counseling to speak of. A positive view in which the influence of culture is regarded as an asset may be entertained. Each of us inherits a wealth of cultural beliefs that influence our cognition. In this sense, culture equips us with a cognitive map to interpret both intracultural and intercultural events. It is incumbent upon us to subject this map to critical scrutiny, from which we may gain insightful knowledge into the workings of our culture through enculturation.

Even when Pedersen (1988) asserts that "all counseling is to some extent multicultural" ( $p$. vii), he has not gone far enough. Like Ibrahim (1991, p. 13), I disagree that all counseling is only "to some extent" multicultural. In a later publication, Pedersen's (1991) case is stated more unequivocally. He argues for a conception of multiculturalism as a generic approach to counseling; accordingly, the multicultural perspective applies to all counseling relationships. My own arguments are in line with this position. In general, the greater the cultural difference between counselor and counselee, the more critical multicultural awareness would be. More fundamentally, without multicultural awareness, self-understanding would be 
limited and incomplete, let alone other-understanding. This is why multicultural awareness figures prominently in any counseling process--more so than counselors have hitherto envisioned.

Implications for Training

There is little dispute about the need for placing greater emphasis on multicultural issues in programs of counseling education. In recognition of this need, educators have introduced specific courses designed for multicultural training in their programs. Here, several points have to be made. First, to be effective, a training program should be guided in its entirety by a theoretical orientation that gives full recognition to the importance of cultural and multicultural processes. It is insufficient to relegate multicultural training to designated courses alone, leaving the rest of the program untouched (i.e., compartmentalized).

Second, it is important to stress that courses in multicultural counseling have relevance beyond counseling practice. In my teaching experience in diverse cultural settings, many students are under the impression that these courses are merely meant to help them to understand and work with clients from a different cultural or ethnic background. They often experience great difficulty in articulating how their lives have been shaped by their own culture. In the United States, for instance, mainstream students often have great difficulty in describing their own cultural background and identity. To reiterate: Self-understanding is a goal integral to multicultural training.

Third, multicultural counseling courses are no substitute for an in-depth knowledge of the culture of clients from a different ethnic background. Such knowledge can be gained only on the basis of a sound general education, enriched by intercultural experiences in real life. How can multicultural awareness be achieved when one is ignorant of the client's culture, and has little or no experience interacting with its members?

Conclusion

I began by attempting to answer the question of what is meant by crossing cultures. I ended with the realization that transcending one's internalized culture is integral to all counseling. To conclude, my thesis is that: (a) All counseling has to confront barriers to interpersonal understanding, (b) interpersonal understanding requires a heightened awareness of internal cultural processes and, therefore, (c) all counseling necessarily entails cultural awareness. Transcending one's own internalized culture through self-examination underlies these processes. It helps to combat culturocentrism and, more fundamentally, egocentrism. Such self-examination is hard work, but the promise is greater self-knowledge and counseling effectiveness. 
References

Bandura, A. (1978). The self system in reciprocal determinism. American Psychologist, 33, 344-358.

Carter, R. T. (1991). Cultural values: A review of empirical research and implications for counseling. Journal of Counseling and Development, 70, 164-173.

Cashmore, J. A., \& Goodnow, J. J. (1986). Influences on Australian parents' values: ethnicity versus socioeconomic status. Journal of Cross-Cultural Psychology, 17, 441-454.

Cohen, J. (1965). Some statistical issues in psychological research. In B. B. Wolman (Ed.), Handbook of clinical psychology (pp. 95-121). New York: McGraw-Hill.

Corey, G., Corey, M. S., \& Callanan, P. (1993). Issues and ethics in the helping professions. Pacific Grove, CA: Brooks/Cole.

de Silva, P. (1993). Buddhist psychology: A therapeutic perspective. In U. Kim \& J. W. Berry (Eds.), Indigenous psychologies: Research and experience in cultural context ( $p p$. 221-239). Newbury Park, CA: Sage.

Dobbins, J. E., \& Skillings, J. H. (1991). The utility of race labeling in understanding cultural identity: A conceptual tool for the social science practitioner. Journal of Counseling and Development, 70, 37-44.

English, H. B., \& English, A. C. (1958). A comprehensive dictionary of psychological and psychoanalytical terms: A guide to usage. New York: Longmans, Green \& Co.

Favazza, A. R., \& Oman, M. (1980). Anthropology and psychiatry. In H. I. Kaplan, A. M. Freedman, \& B. J. Sadock (Eds.), Comprehensive textbook of psychiatry (3rd ed., Vol 1., pp. 485-504). Baltimore, MD: Williams \& Wilkins.

Hakuta, K. (1986). Mirror of language: The debate on bilingualism. New York: Basic Books.

Ho, D. Y. F. (1989). Continuity and variation in Chinese patterns of socialization. Journal of Marriage and the Family, 51, 149-163.

Ho, D. Y. F. (1992). A metatheory of cross-cultural comparisons: Confronting culturocentrism. In U. P. Gielen, L. L. Adler, \& N. A. Milgram (Eds.), Psychology in international perspective: 50 years of the International Council of Psychologists (186-198). Amsterdam/Lisse: Swets \& Zeitlinger.

Ho, D. Y. F., \& Kang, T. K. (1984). Intergenerational comparisons of child-rearing attitudes and practices in Hong Kong. Developmental Psychology, 20, 1004-1016.

Ibrahim, F. A. (1991). Contribution of cultural worldview to generic counseling and development. J ournal of Counseling and Development, 70, 13-19.

Inkeles, A., \& Levinson, D. J. (1954). National character: The study of modal personality and sociocultural systems. In G. Lindzey (Ed.), Handbook of social psychology: Vol. 2. Special fields and applications (pp. 977-1020). Reading, MA: Addison-Wesley.

Kluckhohn, C. (1954). Culture and behavior. In G. Lindzey (Ed.), Handbook of social psychology: Vol. 2. Special fields and applications (pp. 921-976). Reading, MA: AddisonWesley.

LaFromboise, T., Coleman, H. L. K., \& Gerton, J. (1993). Psychological impact of biculturalism: Evidence and theory. Psychological Bulletin, 114, 395-412.

Lambert, W. (1987). The fate of old country values in a new land: A cross-national study of child rearing. Canadian J ournal of Psychology, 28, 9-20.

McGoldrick, M. (1982). Ethnicity and family therapy: An overview. In M. McGoldrick, J. G. Pearce, \& J. Giordano (Eds.), Ethnicity and family therapy (pp. 3-30). New York: Guildford Press.

McLaughlin, B. (1984). Second-language acquisition in childhood. Hillsdale, NJ: Lawrence Erlbaum.

Mio, J. S., \& I wamasa, G. (1993). To do, or not to do: That is the question for White crosscultural researchers. The Counseling Psychologist, 21, 197-212.

Murphy, H. B. M. (1977). Migration, culture and mental health. Psychological Medicine, 7, 677-684.

Myers, L. J., Speight, S. L., Highlen, P. S., Cox, C. I., Reynolds, A. L., Adams, E. M., \& Hanley, P. (1991). I dentity development and worldview: Toward an optimal conceptualization. J ournal of Counseling and Development, 70, 54-63.

Naroll, R. (1970). The culture-bearing unit in cross-cultural surveys. In R. Naroll \& R. Cohen 
(Eds.), A handbook of method in cultural anthropology (pp. 721-765). New York: Natural History Press. (Reprinted in New York: Columbia University Press, 1973.)

Naroll, R. (1971). The double language boundary in cross-cultural surveys. Behavioral Science Notes, 6, 95-102.

Nwachuku, U., \& Ivey, A. (1991). Culture-specific counseling: An alternative training model. Journal of Counseling and Development, 70, 106-111.

Olmedo, E. L. (1979). Acculturation: A psychometric perspective. American Psychologist, 34, 1061-1070.

Pearson, J. C., Turner, L. H., \& Todd-Mancillas, W. (1991). Gender and communication (2nd ed.). Dubuque, IA: Brown.

Pedersen, P. (1988). A handbook for developing multicultural awareness. Alexandria, VA: American Association for Counseling and Development.

Pedersen, P. (1991). Multiculturalism as a generic approach to counseling. Journal of Counseling and Development, 70, 6-12.

Rohner, R. P. (1984). Toward a conception of culture for cross-cultural psychology. Journal of Cross-Cultural Psychology, 15, 111-138.

Sue, D. W., \& Sue, D. (1990). Counseling the culturally different: Theory and practice (2nd ed.). New York: Wiley.

Sundberg, N. D. (1981). Cross-cultural counseling and psychotherapy: A research overview. In A. J. Marsella \& P. B. Pedersen (Eds.), Cross-cultural counseling and psychotherapy (pp. 28-62). New York: Pergamon.

Triandis, H. C. (1972). The analysis of subjective culture. New York: Wiley.

White, L. (1948). Man's control over civilization. Scientific Monthly, 66, 235-247.

Whorf, B. L. (1956). Language, thought and reality: Selected Writings of Benjamin Lee Whorf (J. B. Carroll, Ed.). Cambridge, MA: MIT Press.

Yee, A. H., Fairchild, H. H., Weizmann, F., \& Wyatt, G. E. (1993). Addressing psychology's problems with race. American Psychologist, 48, 1132-1140. 